\title{
Mercury in gas and oil deposits: corrosion problem
}

\author{
Nikolay Mashyanov ${ }^{1 *}$ \\ ${ }^{1}$ Lumex-marketing LLC, 195220 St. Petersburg, Russia
}

\begin{abstract}
Mercury naturally occurs in gas and oil deposits in a wide range of concentrations covering six orders of magnitude: up to $5 \mathrm{mg} / \mathrm{m}^{3}$ in natural gas and up to $600 \mathrm{ppm}(\mathrm{mg} / \mathrm{kg})$ in crude oil. Mercury in hydrocarbons poses a number of technological and environmental problems: contamination of equipment and products with this extremely toxic element, poisoning of catalysts, and initiates intensive corrosion of technological equipment, thereby enhancing accident risk. Metal mercury causes rapid electrochemical corrosion of aluminum alloys (e.g., heat exchangers) and liquid metal embrittlement (LME) of steel leading to heavy accidents. The novel technology based on Zeeman atomic absorption spectroscopy enables rapid selective mercury determination in crude oil, gas condensate, naphtha and natural gas. Examples of the technology application for gas, oil and oil products are presented.
\end{abstract}

\section{Introduction}

Mercury ( $\mathrm{Hg}$ ) naturally occurs in gas and oil deposits in a wide range of concentrations. In some of the 80 examined European and Asian gas fields an increased mercury content, up to $0.5 \mathrm{mg} / \mathrm{m}^{3}$, was found. Mercury in hydrocarbons poses a number of technological and environmental problems. The main goal of this paper is to summarize general regularities of the mercury geochemistry in oil and gas deposits and to present the novel technology based on Zeeman atomic absorption spectroscopy that enables rapid selective mercury determination in gas, crude oil, gas condensate, and naphtha and reduces the risk of corrosion damage during equipment operation.

\section{Few words on mercury geochemistry}

In geochemistry, mercury is classified as a trace element. Mercury abundance in Earth's crust (the Clarke value) is estimated within a range of $30-80 \mu \mathrm{g} / \mathrm{kg}(\mathrm{ppb})$. Average mercury concentration in Global Ocean is evaluated as $0.2-0.3 \mathrm{ng} / \mathrm{L}$ (ppt). Background mercury concentration in air is 1.5 and $1.2 \mathrm{ng} / \mathrm{m}^{3}$ for the Northern and Southern hemispheres, correspondingly [1]. Mercury naturally occurs in all fossil fuels: coal, oil, and natural gas. The mercury concentration in fossil fuels varies in a wide range covering six orders of magnitude [2]:

Coal: $1 \mathrm{ppb}-300 \mathrm{ppm}(1-300,000 \mathrm{ppb})$

Oil: $1 \mathrm{ppb}-600 \mathrm{ppm}(1-600,000 \mathrm{ppb})$

Gas: $1 \mathrm{ng} / \mathrm{m}^{3}-5,000 \mu \mathrm{g} / \mathrm{m}^{3}\left(1-5,000,000 \mathrm{ng} / \mathrm{m}^{3}\right)$.

The ore and hydrocarbon (oil, gas, coal) deposits with elevated mercury concentration are mainly located within global mercury belts $[3,4]$, such as Mediterranean, Central Asian, and Circum-Pacific (Fig. 1).

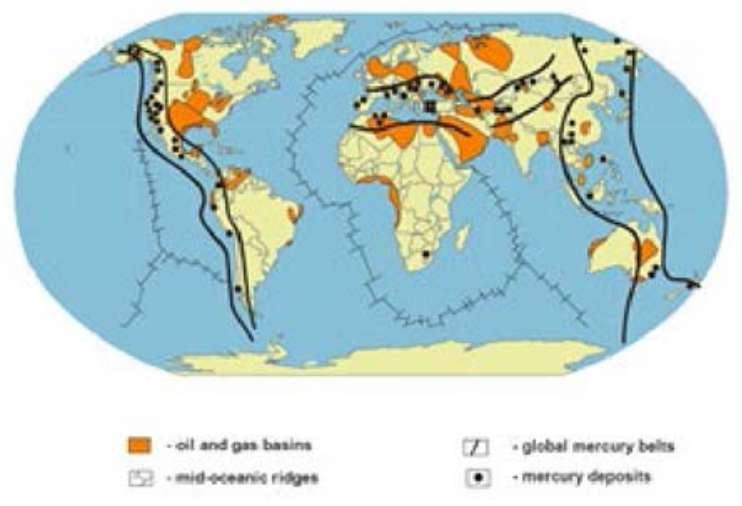

Fig. 1. Oil and gas basins and global mercury belts.

The average $\mathrm{Hg}$ concentration in gas of the 80 studied deposits in European part of Russia, Ukraine, Central Asia, and Croatia is about $2 \mu \mathrm{g} / \mathrm{m}^{3}$ [2]. Only in ten of these deposits $(8 \%)$, the $\mathrm{Hg}$ concentration was above $10 \mu \mathrm{g} / \mathrm{m}^{3}$. The highest mercury content occurs in the deposits located in crossing deep faults zones that indicates the contribution of mercury-enriched deep mantle fluids in the gas pools formation $[4,5]$. In such objects, a big amount of liquid mercury can accumulate in the process equipment. Basing on the published data and own studies $[2,4,5]$, the following basic regularities were discovered.

Concentration:

- The mercury content in hydrocarbon gases varies over a wide range - from values less than $1 \mathrm{ng} / \mathrm{m}^{3}$ up to $5,000 \mu \mathrm{g} / \mathrm{m}^{3}$.

- The evident spatial-temporal variability of mercury content in gases was discovered [6].

- The difference of the $\mathrm{Hg}$ concentration in the vertical direction can be as large as four orders of magnitude 
from top to bottom of production layers.

- The year-to-year $\mathrm{Hg}$ concentration from the same operating wells can change as much as $2-10$ times.

- The dominant form of mercury in hydrocarbon gases is elementary $\operatorname{Hg}(0)$ vapor.

Geological features [4]:

- There is absolutely no stratigraphic or lithologic control found in Hg-bearing gases in any of oil-gas provinces.

- The general feature of these deposits is their localization in the crossing zones of deep faults and transcontinental lineaments (rifts).

- There is a tendency of the Hg concentration increase with the depth of productive layers observed in oilgas provinces, as well as in separate deposits.

These regularities and spatial-temporal variability of mercury in gas pools should be taken into account for the assessment of challenges caused by mercury.

\section{Environmental and health problems}

Mercury in natural hydrocarbon gas poses a number of technological and environmental problems related to the health and environmental regulation; gas production, processing, piping, liquefaction, and also to the equipment contamination and accident risk.

Besides process gas utilization, mercury can release to the environment from gas flaring and leakage [7], with drilling and produced water, and especially during maintenance and disposal of contaminated equipment, when up to dozens of kilos of metal mercury have to be removed and can be spilled (Fig. 2):

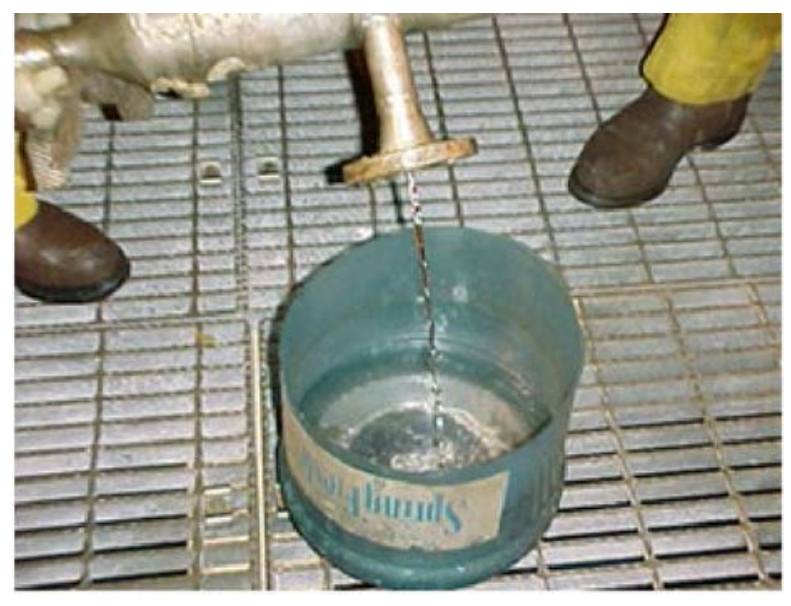

Fig. 2. Liquid mercury removal during gas equipment maintenance. Courtesy of Petronas.

Due to its high toxicity, mercury is the subject of strict environmental and health safety regulations. The $\mathrm{Hg}$ limits for the environmental media, such as soils, water, air, foodstuff, and human body, are listed in national regulations and the WHO recommendation. However, there is no generally recognized environmental regulation related to mercury content in gas and other fossil fuels. For example, there is no legal limit for mercury concentrations in natural gas in
Europe; the gas suppliers in Germany have set a threshold of $28 \mu \mathrm{g} / \mathrm{m}^{3}$ for purchasing gas from the producers.

Mercury is sticking to most of the materials that are used in gas industry, contaminating pipelines and processing equipment. Many smelters set a $2 \mathrm{mg} / \mathrm{kg}$ limit on mercury in scrap steel to avoid mercury emissions and damage to the off-gas clean-up filters; with higher concentrations requiring disposal as hazardous waste [8]. The difficulties in disposing of a material classified as hazardous waste means that some natural gas pipeline operators set entry specifications that limit mercury content in gas.

Taking into account mercury mobility and its longterm air transfer, an indirect effect on humans and environment should be also considered: once released, $\mathrm{Hg}$ accumulates in deponent media (soils, sediments, biota) creating dangerous levels for humans.

\section{Technological problems. Corrosion}

Besides the environmental and health issues, the elevated level of mercury creates a number of technological issues. Mercury, as some other heavy metals, spoils catalysts (e.g. palladium based) that are used in oil and gas processing. The $\mathrm{Hg}$ poisoning shortens the catalysts life and may require an unplanned and premature catalyst change-out that rises production costs. Mercury also can create bias in control sensors readings, such as humidity sensors.

The greatest concern is the intensive corrosion of technological equipment initiated by liquid mercury and enhancing greatly an accident risk. As it was mentioned, in a case of the high mercury content in natural gas (hundreds $\mathrm{ng} / \mathrm{m}^{3}$ ), big quantity of metal mercury can accumulate in the equipment during gas production and processing (see Fig. 2). However, liquid mercury can appear during liquefaction of the gas even with a low $\mathrm{Hg}$ content (dozens $\mathrm{ng} / \mathrm{m}^{3}$ ) when the volume of a liquefied gas is 600-times decreasing. That is why, for liquefaction, mercury content in gas has to be brought down to the value below $10 \mathrm{ng} / \mathrm{m}^{3}$.

Metal mercury causes rapid electrochemical corrosion of aluminum alloys (e.g., heat exchangers) and liquid metal embrittlement and cracking of steel leading to catastrophic events such as the known accidents at the Moomba gas plant in Australia and Skikda LNG plant in Algeria, both happened in January 2004 [9, 10].

In Moomba, the gas released due to a failure of a heat exchanger inlet nozzle in the liquids recovery plant. The failure of the inlet nozzle was due to liquid metal embrittlement of the aluminum heat exchanger by condensed elemental mercury. Direct damage was assessed as \$5 million.

In Skikda, a steam boiler that was part of an LNG production plant exploded, triggering a second, more massive vapor-cloud explosion and fire (Fig. 3). The explosions and fire destroyed three of six gas liquefaction trains and caused 27 deaths, 74 injuries, and material damage of $\$ 30$ million. 


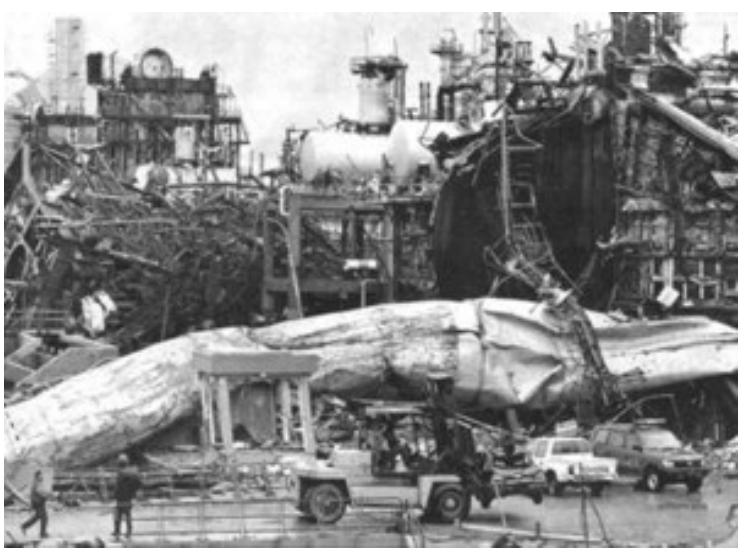

Fig. 3. Skikda, Algeria, January 19, 2004: LNG Plant explosion due to liquid metal embrittlement [10].

\section{Mercury determination}

Mercury in the gas and oil industry has to be determined in formidable diversity of samples: raw gaseous and liquid hydrocarbons, strata and waste waters, absorbents, sludge, contaminated equipment (air, washouts, steel), etc.

Mercury that enters with a raw gas to a processing plant is distributed across the different gas and liquid streams depending on the type of technological scheme that usually includes water, condensate, and acid gases removal by the inlet separation, cooling in heat exchangers for natural gas liquids recovery. For gases with a high mercury concentration and for LNG production, the technological cycle includes special control units for mercury removal (MRU) where on-line mercury monitoring is required.

The most universal tool for mercury determination in gaseous, liquid and solid media to be controlled in the gas and oil industry is based on Zeeman atomic absorption spectroscopy (ZAAS) that enables rapid selective mercury determination in crude oil, gas condensate, and naphtha as well as continuous mercury monitoring in natural gas [11].

The specific feature of Zeeman background correction is high selectivity of measurement enabling direct mercury determination in complex matrices that exclude intermediate mercury pre-concentration on traps (commonly gold traps), which is used in conventional techniques.

The mercury concentration in natural gas is measured with the RA-915M analyzer or RA-915AMNG mercury monitor continuously, in real time in gas flow that directly enters to the analytical cell from a pipe or from a sampling container (cylinder, Tedlar ${ }^{\circledR}$ bag). The measurement with mercury pre-concentration on the gold traps is also possible using pyrolysis attachment PYRO-915. This set of direct pyrolysis enables fast direct determination of the $\mathrm{Hg}$ concentration in liquid hydrocarbons, such as crude oil, condensate, naphtha, coal, etc. $[11,12]$.

ZAAS is the most versatile analytical technique that can be applied to the mercury determination at all the stages of the gas and oil production, processing, and transportation. The technique provides mercury measurement in all possible range of concentrations:
Gases
$0.5-200,000 \mathrm{ng} / \mathrm{m}^{3}$
Crude oil
$5-10,000 \mu \mathrm{g} / \mathrm{kg}(\mathrm{ppb})$
Naphtha
$0.1-1,000 \mu \mathrm{g} / \mathrm{kg}(\mathrm{ppb})$
Water
$0.2 \mathrm{ng} / \mathrm{L}-2 \mathrm{mg} / \mathrm{L}(0.2 \mathrm{ppt}-2 \mathrm{ppm})$

Mercury determination in gas is a quite complicated task for conventional techniques due to the variability of gas composition, presence of interfering components. In a case of ZAAS, it is possible to determine mercury concentration in real time in a gas flow with response time of $1 \mathrm{~s}$ (Fig. 4):

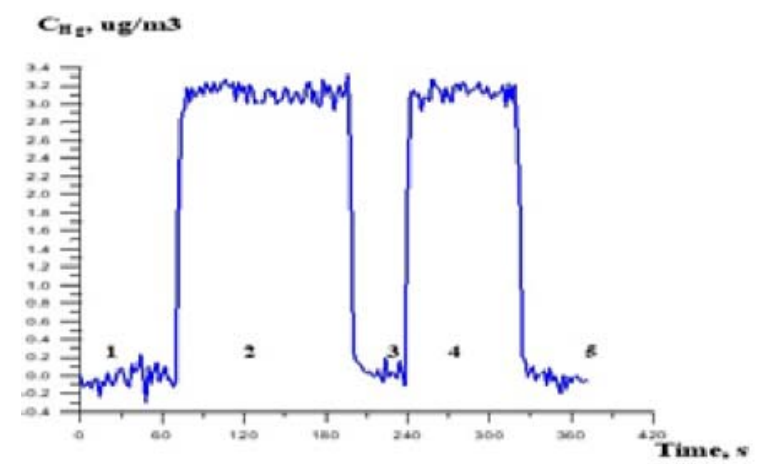

Fig. 4. Mercury in gas, real time measurement. 1, 3, 5- zero control; 2, 4-measurement.

Direct analyses show good agreement with the gold trap pre-concentration ASTM, ISO JLPGA standard methods. For example, the comparison of ZAAS and JLPGA data for mercury determination in liquefied petroleum gas (LPG) is illustrated in Fig. 5:

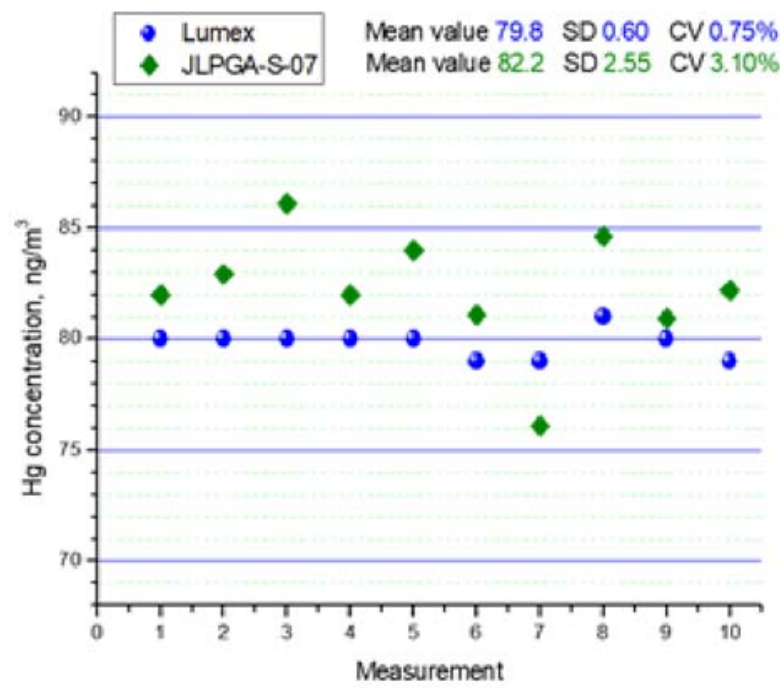

Fig. 5. Mercury in LPG. Comparison of the direct measurement (Lumex) and measurement with the $\mathrm{Hg}$ preconcentrating on a gold trap (JLPGA-S-07). The data are kindly provided by Intertek Testing Services, Singapore.

The technology of on-line mercury monitoring in natural gas is successfully used at a number of gas processing and LNG plants to minimize the negative technological and environmental effects caused by the elevated mercury concentration in natural gas. 


\section{Conclusion}

The mercury concentration in all fossil fuels: coal, oil, and natural gas can vary in a wide range. The elevated level of mercury concentration is observed in deposits located within deep fault zones (global mercury belts).

The elevated mercury concentration in natural gas creates a number of technological and environmental problems, the main of which is the intensive corrosion of technological equipment enhancing accident risk. That is why the mercury content affects the product specification and pricing. The novel technology based on Zeeman atomic absorption spectroscopy is a universal tool for mercury determination at all stages of the oil and gas production.

\section{References}

1. Global Mercury Assessment 2018, UN Environment Programme, Geneva (2019)

2. N.A. Ozerova, N.R. Mashyanov, V.V. Ryzhov, et al., In: Mercury Contaminated Sites. Springer, 237246 (1999)

3. V.A. Smirnov, V.A Kuznetsov, V.P. Fedorchuk (eds.), Metallogeny of Mercury. Nedra, Moscow (1976)

4. N.A. Ozerova, In: Baeyens W., Ebinghaus R., Vasiliev O. (eds), Global and Regional Mercury Cycles: Sources, Fluxes and Mass Balances, NATO ASI, 21, 463-474 (1996)

5. N. Ozerova, N. Mashyanov, V. Ryzhov, Yu. Pikovsky, RMZ, 51, 1, 181-184 (2004)

6. V.V Ryzhov, N.R. Mashyanov, N.A. Ozerova, S. E. Pogarev, STOTEN, 304, 1-3, 145-152 (2003)

7. Z. Spiric, N.R. Mashyanov. Mercury measurements in ambient air near natural gas processing facilities. Fresenius J Anal Chem. 366, 5, 429-432 (2000)

8. P.J.H. Carnell., V.A Row, R. McKenna, A re-think of the mercury removal problem for LNG plants (2007)

9. Handbook of Liquefied Natural Gas, Elsevier, 359435 (2014)

10. A. Groysman, Corrosion Problems and Solution in Oil Refining and Petrochemical Industry. Springer (2016)

11. S. Sholupov, S. Pogarev, V. Ryzhov, N. Mashyanov, A. Stroganov, Fuel Process. Technol. 85, 473- 485 (2004)

12. N. Mashyanov, S. Pogarev, E. Panova, N. Panichev, V. Ryzhov, Fuel 203, 973-980 (2017) 